\title{
Anencephaly: A 3 Years Study
}

\author{
Dr.Aruna.Eslavath(MD), Dr. Ranga Rao.Diddi(MD), \\ Dr.Kalyan Chakravarthy.Valabhaneni(MD).
}

\begin{abstract}
Background: Anencephaly is a neural tube defect which is due to the defective closure of cranial neuropore. It is associated with other systemic anomalies in most of the cases. This study was undertaken to determine the incidence of anencephaly among congenital malformations at autopsy, associated systemic anomalies, maternal age and sex of the fetus.
\end{abstract}

Keywords:- Anencephaly, Spinabifida, Omphalocele, Craniospinal rachinoschisis,

\section{Introduction}

Anencephaly is a neural tube defect (NTD) caused by a failure of closure of the cranial neuropore between the third and fourth week of gestation (23rd and 26th embryonic day), resulting in the absence of a major portion of the brain, skull, and scalp. ${ }^{(1)}$ In anencephaly, as the influence of the expanding brain is removed, it causes secondary adaptive alterations in the cranial base. The squamo-occipital bones are under developed compared with the normal standards ${ }^{(2)}$. Anencephaly can be diagnosed by ultrasound examination (USG) and by elevated maternal alpha feto protein(AFP) level, but pathological examination of the abortus is needed, as in most cases anencephaly is also associated with systemic anomalies ${ }^{(3)}$. Anencephaly was the first fetal malformation diagnosed prenatally by Campbell etal using trans-abdominal ultrasound ${ }^{(4)}$.

The cause of anencephaly is disputed. Generally, neural tube defects do not follow direct pattern of heredity, though there is some indirect evidence of inheritance ${ }^{(5)}$, and recent animal models indicate a possible association with deficiencies of the transcription factor TEAD2 ${ }^{(6)}$. Studies show that a woman who had one child with a neural tube defect such as anencephaly will also have 3\% risk of having another child with a neural tube defect ${ }^{(7)}$. Women taking certain medications for epilepsy and women with insulin-dependent- diabetesmellitus have a higher $\operatorname{risk}^{(8)}$.

According to recent studies, addition of folic acid to the diet of women of child-bearing age has significantly reduced the risk of neural tube defect to $0.03 \%{ }^{(9)}$. Hibbard and Smithells ${ }^{(10)}$, were first to suggest a possible link between folate deficiency and these defects, but other workers have failed to demonstrate this correlation.

This study was undertaken to determine the incidence of anencephaly among congenital malformations at autopsy, associated systemic anomalies, maternal age and sex of the fetus with anencephaly.

\section{Materials And Methods}

This study was conducted in our institute over a period of 3 years from June 2010 to May 2013. Autopsies were performed after obtaining informed consent. The autopsies included clinical findings, external examination, photography and internal examination. The cases included stillbirth, spontaneous and therapeutic abortion.

\section{Results}

Out of 103 cases of fetal autopsies, 34 cases showed congenital malformations(33\%), out of these $17(50 \%)$ cases showed CNS anomalies, out of these 17 cases of CNS anomalies $9(13.8 \%)$ cases of anencephaly were observed, of which 6 cases showed associated systemic anomalies. Most commonly associated anomaly was spina-bifida followed by gastrointestinal anomalies.

Table:-1 Details of anencephaly case

\begin{tabular}{|c|c|c|c|c|c|}
\hline Case & $\begin{array}{l}\text { Age of } \\
\text { mother } \\
\text { (years) }\end{array}$ & Parity & Gestational age & Sex of fetus & Associated anomaly \\
\hline 1 & 20 & Primi & 20 & Male & - \\
\hline 2 & 22 & Gravid 3 & 20 & Female & $\begin{array}{l}\text { spina bifida, hypoplasia of thyroid and bilateral } \\
\text { adrenals. }\end{array}$ \\
\hline 3 & 24 & Primi & 18 & Male & One artery and one vein \\
\hline 4 & 20 & Primi & 32 & Male & $\begin{array}{l}\text { Multiple craniofacial anomalies, musculoskeletal } \\
\text { anomalies, meningocele, omphalocele, B/L adrenal } \\
\text { atrophy, multilobed liver. }\end{array}$ \\
\hline 5 & 20 & Primi & 24 & Female & Cleft lip \&palate, spina bifida, short and wide neck \\
\hline
\end{tabular}


Anencephaly: A 3 Years Study

\begin{tabular}{|l|l|l|l|l|l|}
\hline & & & & & omphalocele \\
\hline 6 & 23 & Second & 40 & Female & Absent adrenals, enlarged spleen and thyroid. \\
\hline 7 & 28 & Second & 19 & Female & Craniospinal rachischisis \\
\hline 8 & 20 & Primi & 24 & Female & Single umbilical artery \\
\hline 9 & 29 & Second & 12 & Male & - \\
\hline
\end{tabular}

The Minimum age of the mother observed in our study was 20 yrs and maximum was 29 yrs. Out of 9 mothers 5 were primigravida (55.5\%), 3 were second gravida $(33.3 \%)$, one was gravid $3(11.1 \%)$. Gestational age ranged from 12 to 40 weeks with mean of 23 wks. Out of 9 fetuses, 5 were female (55.5\%), 4 were male(44.4\%).[Table 1] Out of 9 cases, 7cases showed associated anomalies(77.7\%). Other Central Nervous system anomalies observed were spinabifida in two cases(fig-4), craniospinal rachinoschisis in one case and meningocele in one case. In one case the anomaly identified in the face were cleft lip and cleft palate(fig-3). Cardiovascular anomaly observed was single umbilical artery in three case. Gastrointestinal anomaly observed were omphalocele in 2 cases [Fig-3]. In one case anencephaly was associated with bilateral hypoplasia of adrenals and in another one case the adrenals were completely absent [fig-2]. In one case there was hypoplasia of thyroid and in another one case thyroid and spleen were enlarged. All the cases showed area cerebrovasculosa. Out of 9 cases 1 case was associated with multiple anomalies involving CNS, GIT, musculoskeletal, internal viscera (fig-1).

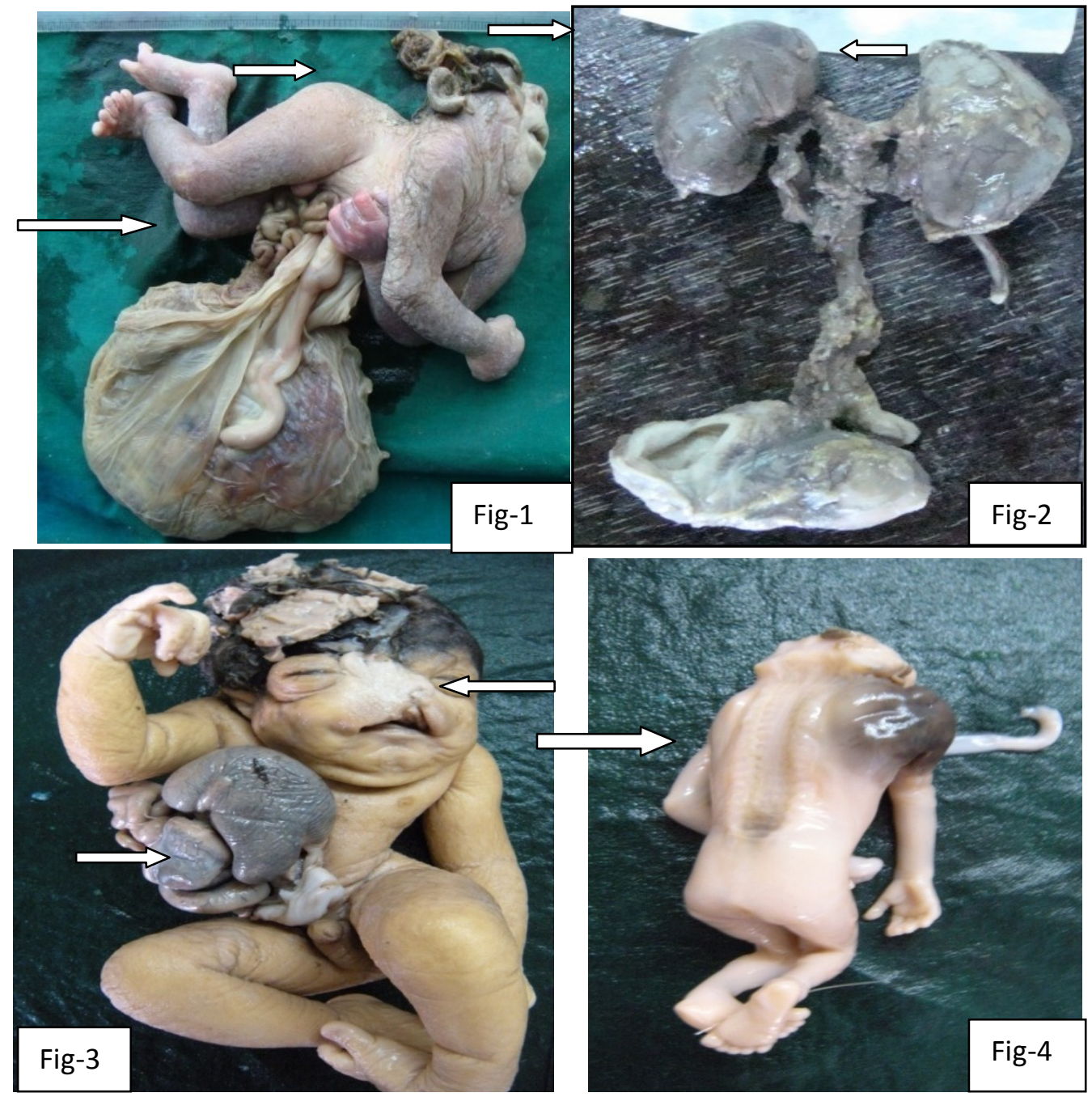

Fig-1 Anencephaly with multiple craniofacial anomalies, omphalocele.

Fig-2 Absent bilateral adrenals.

Fig-3 Anencephaly with cleft lip \& omphalocele

Fig-4 Anencephaly with craniospinal rachinoschisis 

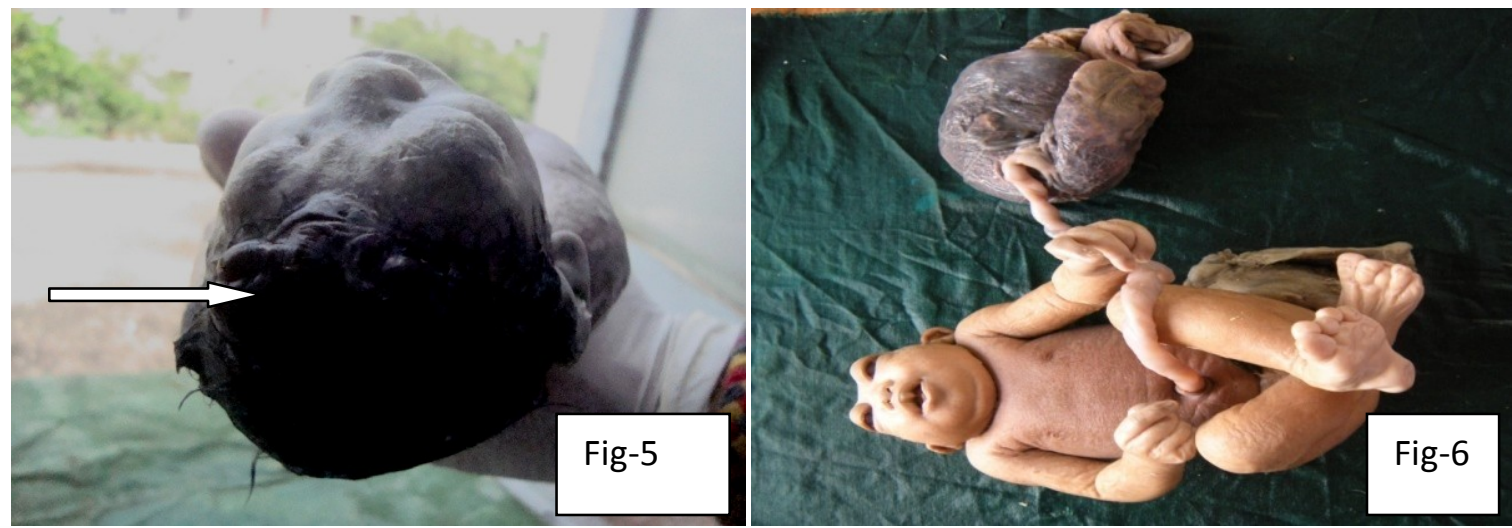

Fig-5 Anencephaly with cerebrovasculosa

Fig-4 Anencephaly fetus

\section{Discussion}

The incidence of anencephaly varies greatly among different populations. It is 1.8 per 1000 live births in India $^{(11)}, 0.54$ per 1000 births in Singapore ${ }^{(14)(12)}, 12$ per 10,000 in Iran , 10.4 per 10,000 in China. The incidence is high in fetuses born to mothers below 19 years and over 40 years of age. Caffey et $\mathrm{al}^{(13)}$,Horowitz ${ }^{(14)}$,Edward ${ }^{(15)}$ and also Golalipour et $\mathrm{al}^{(16)}$ observed prevelance of anencephaly to be more in women below 20 years and above 35 years. In our study the minimum age of the mother was 20 years and the maximum age was 29 years, and our findings are consistant with published literature ${ }^{(17-18)}$.

The association between anencephaly and birth order is described as U-shaped ${ }^{(19)}$, however, Elwood et.al (1978) reported that the frequently noted U-type relationship of anencephalus risk with maternal parity was produced by a combination of two influences, i.e a decrease in risk with previous live born 'healthy' pregnancies and an increased in risk with previous 'unhealthy' pregnancies as still births or infant deaths. In our cases, there were no previous unhealthy pregnancies. According to other studies anencephaly was common in primigravid. In our study 5 out of 9 cases occurred in primigravid. Hence our findings are comparable to the findings published previously ${ }^{(17}$.

Most of the mothers were from rural area and they were agricultural labours. They had regular antenatal checkups outside and took iron and folic acid, however they did not get ultrasound study done. The cases were diagnosed at the time of ultrasound examination during their visit to our hospital and they were advised medical termination of pregnancy. Some of the cases were spontaneous abortion and some were still born. The gestational age ranged from 12 to 40 weeks.

Anencephaly is more common in female fetus. Review of literature showed similar findings, and we also noticed female preponderance (55\%). However there are few studies showing male preponderance. coffey et al (1957) reported that the percentage of male with anencephaly varied from $19.5-48.4 \%{ }^{(13)}$. In our study, male with anencephaly constituted $44 \%$.

Anencephaly is associated with anomalies of various systems. Out of 9 cases presented here, 4 cases showed other CNS anomalies. Spinabifida was seen in 2 cases, craniospinal rachischisis in one case and meningocele in one case. Spinabifida is the most common CNS anomaly associated with the anencephaly . craniospinal rachischisis is the most severe type of anencephaly where area cerebrovasculosa and area medullo vasculosa will fill both cranial defects and the spinal column. Craniospinalrachischisis is characterized by anencephaly accompanied by bony defects in the spine with exposure of neural tissue. All the cases of anencephaly showed "area cerebrovasculosa".

GIT anomalies were the $2^{\text {nd }}$ most common anomalies associated with anencephly. In our study GIT anomalies included cleft lip and cleft palate, omphalocele.

Anencephaly is also frequently associated with defects in many of the endocrine glands. In our study we have noticed hypoplasia of both adrenals and thyroid. In two cases there were absent adrenals. One of the cases showed hyperplasia of the thyroid.

Comparision with the other studies ${ }^{(18)}$ 


\begin{tabular}{|c|c|c|c|c|c|c|c|c|}
\hline System & David etal & Vare et al & $\begin{array}{l}\text { Golipure } \\
\text { et al }\end{array}$ & $\begin{array}{l}\text { Tan et } \\
\text { al }\end{array}$ & $\begin{array}{l}\text { Nielsen } \\
\text { et al }\end{array}$ & $\begin{array}{l}\text { Davod } \\
\text { et al }\end{array}$ & $\begin{array}{l}\text { Pandura } \\
\text { nga et al }\end{array}$ & Present study \\
\hline $\begin{array}{l}\text { Total anomaly } \\
\text { Head \& neck }\end{array}$ & 33.5 & $\begin{array}{l}\text { Not } \\
\text { mentioned }\end{array}$ & 42.9 & 9.4 & 43 & 23.6 & $73 \%$ & 77.7 \\
\hline RS & 3.5 & 7.5 & 3.5 & $\mathrm{NO}$ & 14 & 4.6 & 2.5 & 11.1 \\
\hline CVS & 1 & NAD & NAD & 3 & NAD & 0.6 & 2.5 & NAD \\
\hline GIT & 5.8 & 7.5 & 1.7 & 3 & 4.75 & 11 & 14.5 & 33.3 \\
\hline RENAL & 8 & 32 & 5.3 & 29 & NAD & 5.7 & 14.5 & 22.2 \\
\hline SKELETAL & 16.3 & 27 & 3.5 & 3 & 12 & 5.2 & NAD & NAD \\
\hline GENITAL & 1.5 & 14.5 & 8.9 & 20 & 16.5 & 1.7 & 14.5 & 11.1 \\
\hline DIAPHRAGMA & 0.6 & 5 & NAD & NAD & NAD & 0.6 & 12 & NAD \\
\hline TIC & 2.7 & & NAD & NAD & 2.3 & 6.3 & 1 & NAD \\
\hline HERNIA & (8cases) & (2 cases) & & & & $\begin{array}{l}(11 \\
\text { cases) }\end{array}$ & Case & \\
\hline
\end{tabular}

NAD $=$ No anomaly detected

\section{Conclusion}

We conclude from our study that Anencephaly is common in women conceiving at $3^{\text {rd }}$ decade of life . Most common in female fetus, commonly noticed in the primigravida. Central nervous system anomalies are the commonly associated anomalies. Anencephaly is efficiently diagnosed by ultrasound examination (USG) during early days of pregnancy, but pathological examination of the abortus is needed, as in most cases anencephaly is also associated with systemic anomalies. This helps in counseling the parents and in planning next pregnancy.

\section{References}

[1]. Moore LK, Persaud TV.Editors. The developing Human. Philadelphia: Saunders; 1998.p.478-479.

[2]. Trenouth MJ. Craniofacial shape in the anencephalic human fetus, journal of anatomy. 1989;165;215-224

[3]. Vare AM, Bansal PC. Anencephaly. An Anatomical study of 41 anencephalies. Indian J.Pediatr 1971;38;301-305[PUB MED]

[4]. Campbell S, etal. Anencephaly early ultrasonic diagnosis \& active management, Lancet;1972;1226-1227.

[5]. Shaffer, Lisa G.; Marazita, Mary L.; Bodurtha, Joann; Newlin, Anna; Nance, Walter E. "Evidence for a major gene in familial anencephaly". American Journal of Medical Genetics 1990:36 (1): 97-101.

[6]. Kaneko, Kotaro J.; Kohn, Matthew J.; Liu, Chengyu; Depamphilis, Melvin L. "Transcription factor TEAD2 is involved in neural tube closure". Genesis 2007: 45 (9): 577-87.

[7]. Cowchock, S.; Ainbender, E.; Prescott, G.; Crandall, B.; Lau, L.; Heller, R.; Muir, W. A.; Kloza, E. et al. "The recurrence risk for neural tube defects in the United States: A collaborative study". American Journal of Medical Genetics 1980: 5 (3): $309-14$.

[8]. "Anencephaly". Genetics Home Reference. National Institutes of Health. 22 August 2011.

[9]. Ratcliffe, Stephen D., ed. Family medicine obstetrics 2008 (3rd ed.). Philadephia: Mosby Elsevier.

[10]. Hibbard ED, Smithells RM. Folic acid metabolism and human embryopathy. Lancet $1965 ; \mathrm{i}: 1254-6$.

[11]. Mahadevan B, Bhat BV.Neural tube defects in Pondicherry. Indian J Pediatr 2005; 72:557-9.

[12]. Tan KB, Tan SH, Tan KH,Yeo GS. Anencephaly in Singapore: a ten year series 1993 -2002. Singapore Med J 2007;48:12-5.

[13]. Caffey VP, Jessop WJ. A study of 137 cases of anencephaly. BR J Prev Soc Med 1957;11:174-80.

[14]. Horowitz I,Mc Donald AD. Anencephaly and spina bifida in the province of Quebec. Can Med Assoc J. 1969 Apr 26;100(16): 74855

[15]. Edward JH. Congenital malformations of the central nervous system in Scotland. Br J Prev Soc Med 1958;12:115-30.

[16]. Golalipour MJ, Najafi L, Keshtkar AA. Prevalence of Anencephaly in Gorgan, northern Iran. Arch Iran Med 2010;13:34-7.

[17]. Vare AM,Bansal PC.Anencephaly: An anatomical study of 41 anencephalics. Indian J Pediatr 1971;38:301-5.

[18]. Panduranga C, Kangle R, Suranagi W, Pilli GS, Patil PV. Anencephaly: A pathological study of 41 cases. J Sci Soc 2012; $39: 81$-4.

[19]. Je G. Chi and Kyung SOO Park. Pathological Study On Anencephaly (10 Autopsy Cases)The Seoul Journal of Medicine,sept.1982,vol 23;3;392-405. 